University of Nebraska - Lincoln

DigitalCommons@University of Nebraska - Lincoln

USDA Wildlife Services - Staff Publications

U.S. Department of Agriculture: Animal and Plant Health Inspection Service

2020

\title{
Timing and extent of crop damage by wild pigs (Sus scrofa Linnaeus) to corn and peanut fields
}

\author{
C. M. Boyce \\ University of Georgia, Savannah River Ecology Laboratory \\ Kurt C. Vercauteren \\ APHIS, kurt.c.vercauteren@usda.gov \\ James C. Beasley \\ University of Georgia, beasley@srel.uga.edu
}

Follow this and additional works at: https://digitalcommons.unl.edu/icwdm_usdanwrc

Part of the Natural Resources and Conservation Commons, Natural Resources Management and Policy Commons, Other Environmental Sciences Commons, Other Veterinary Medicine Commons, Population Biology Commons, Terrestrial and Aquatic Ecology Commons, Veterinary Infectious Diseases Commons, Veterinary Microbiology and Immunobiology Commons, Veterinary Preventive Medicine, Epidemiology, and Public Health Commons, and the Zoology Commons

Boyce, C. M.; Vercauteren, Kurt C.; and Beasley, James C., "Timing and extent of crop damage by wild pigs (Sus scrofa Linnaeus) to corn and peanut fields" (2020). USDA Wildlife Services - Staff Publications. 2337. https://digitalcommons.unl.edu/icwdm_usdanwrc/2337

This Article is brought to you for free and open access by the U.S. Department of Agriculture: Animal and Plant Health Inspection Service at DigitalCommons@University of Nebraska - Lincoln. It has been accepted for inclusion in USDA Wildlife Services - Staff Publications by an authorized administrator of DigitalCommons@University of Nebraska - Lincoln. 


\title{
Timing and extent of crop damage by wild pigs (Sus scrofa Linnaeus) to corn and peanut fields
}

\author{
C.M. Boyce ${ }^{\mathrm{a}, *}$, K.C. VerCauteren ${ }^{\mathrm{b}}$, J.C. Beasley ${ }^{\mathrm{a}}$ \\ ${ }^{\text {a }}$ University of Georgia, Savannah River Ecology Laboratory, D.B. Warnell School of Forestry and Natural Resources, P.O. Drawer E, Aiken, SC, 29802, USA \\ ${ }^{\mathrm{b}}$ USDA/Wildlife Services, National Wildlife Research Center, 4101 LaPorte Ave., Fort Collins, CO, 80521, USA
}

\section{A R T I C L E I N F O}

\section{Keywords:}

Agriculture

Crop damage

Damage assessment

Depredation

Invasive

Wildlife damage management

\begin{abstract}
A B S T R A C T
The global expansion of wild pigs over the last few decades has resulted in an increase in extent and distribution of damages to crops, placing a growing strain on agricultural producers and land managers. Despite the extent of wild pig damage to agriculture, there is little data regarding timing and spatial variability of damage to corn (Zea mays Linnaeus) and we found no data regarding the effect of these factors on peanuts (Arachis hypogaea Linnaeus). Our objective was to determine the timing and extent of wild pig damage to corn and peanut fields, as well as the extent to which local habitat attributes are useful predictors of damage to these crops. During 2017-2018 we performed ground-based surveys throughout the growing season for 29 corn and 41 peanut fields in South Carolina, USA to determine the most important growth stages for wild pig depredation in both crops. Damage to corn peaked shortly after planting during the seedling stage, fell to nearly zero during V4-V6 stages, and resumed during the silk and mature stages. Peanut damage was almost exclusively limited to the seedling stage. Landscape models for both crops identified the extent of forested and wetland areas surrounding crop fields as the most important attributes positively associated with wild pig damage, while the amount of adjacent agricultural area and paved roads were associated negatively. The number of wild pigs identified by remote cameras also was an important indicator of the extent of damage to peanut fields. Results suggest management efforts to limit crop depredation by wild pigs should be targeted shortly prior to planting. Further, because damage was positively associated with the availability of wetland and forest habitats, our results suggest agricultural damage by wild pigs may be most severe near areas of preferred native habitats.
\end{abstract}

\section{Introduction}

Wild pigs (Sus scrofa Linnaeus) - known as wild boar in their native ranges - have one of the most extensive geographic distributions of any large mammal, occurring on all continents except Antarctica (Barrios-Garcia and Ballari, 2012). Within North America, wild pigs have existed on the landscape since the mid-1500s, although their distribution remained relatively stable for several centuries (Mayer and Brisbin, 2009). Beginning in the 1990s wild pig populations began increasing rapidly in size and distribution (Bevins et al., 2014; Snow et al., 2017; Mayer and Beasley, 2018), with the current estimate within U.S. exceeding 6.9 million individuals (Lewis et al., 2019). While range expansion has contributed to the rapid surge in population expansion within North America, illegal translocation of animals is widely regarded as a the most substantive driver of this increase (Gipson et al., 1998; Bevins et al., 2014, Tabak et al., 2017; Beasley et al., 2018). Similar population increases have been reported in other parts of their invasive and native ranges over the last few decades, although in Europe a combination of warmer winters and increased mast and maize availability have had the most critical influence on wild boar population growth (Saez-Royuela and Telleria, 1986; Geisser and Reyer, 2005; Massei et al., 2014).

Concomitant with increasing populations of wild pigs, over the last few decades the extent and distribution of damages associated with this species have increased markedly (Bevins et al., 2014). For example, wild boar damage to agriculture increased by $1600 \%$ from 1971 to 2004 in Luxembourg (Schley et al., 2008). Thus, the increase in range and population of wild pigs and wild boar should be seen as a global threat to agriculture and ecosystem health (Spear and Chown, 2009). Wild pigs overturn the soil while foraging (i.e. rooting), increasing erosion and altering the soil structure and subsequent nutrient cycle (Wirthner et al., 2011; Palacio et al., 2013), which can have cascading impacts on native

\footnotetext{
* Corresponding author.

E-mail address: cmboyce@gmail.com (C.M. Boyce).
} 
communities and ecosystems (Barrios-Garcia and Ballari, 2012). Disturbances caused by rooting can have both direct and indirect effects on native plant communities, while their opportunistic predatory behavior poses a risk to invertebrate and vertebrate communities, including small mammals, ground nesting birds, snakes, insects, and salamanders (Massei and Genov, 2004, Wilcox and van Vuren, 2009). In particular, given their behavioral and dietary plasticity, wild pigs are able to exploit seasonally available resources such as cereal crops (Herrero et al., 2007; Schley and Roper, 2003). Indeed, studies in Spain have shown wild boar selectively target cornfields (Zea mays Linnaeus) over natural food sources when available (Herrero et al., 2007). Consequently, wild pig damage to agriculture is extensive throughout their native and invasive range. For example, wild pigs cause an estimated $\$ 61$ million of damage to corn and $\$ 40$ million of damage to peanuts (Arachis hypogaea Linnaeus) annually across 11 states in the U.S. alone (Anderson et al., 2016).

Wildlife damage to crops is typically variable in both space and time, with damage often concentrated during specific plant growth stages (Garrison and Lewis, 1987; Chiyo et al., 2005; Humberg et al., 2007; Bleier et al., 2017). For example, damage to a variety of crops in Africa and Asia by elephants (Loxodonta Africana Blumenbach and Elephas maximus Linnaeus, respectively) and pig species (Sus scrofa Linnaeus, Potamocherus larvatus Cuvier, and Phacochoerus africanus Gmelin) is often less severe during intermediate growth stages compared to either the seedling or mature stage (Gross et al., 2018). Similarly, wild boar primarily consume crop plants when nutritional value is maximal, such as immediately after planting or just prior to harvest, with a reduction in consumption and damage between these peaks (Gimenez-Anaya et al., 2008; Schley et al., 2008; Bleier et al., 2017). Wildlife damage to crops also is highly variable spatially, with both inter- and intra-field damage often correlated with habitat attributes associated with animal movements or preferred non-agricultural resources (e.g., forest edges, riparian areas; DeVault et al., 2007; Retamosa et al., 2008, Thurfjell et al., 2009). Although ecological generalists, wild pig movements are often driven by a combination of land cover and food abundance (Morelle et al., 2015). Indeed, Lombardini et al. (2017) found wild boar damage, generalized to a wide variety of crops in Sardinia, was most severe in proximity to forest and shrub edge. Similarly, Cai et al. (2008) found distance to forest and streams impacted the probability of wild boar damage to corn, potato (Ipomoea batatas Lamarck), and wheat (Triticum aestivum Linnaeus) in China.

Despite the extent of economic impacts of wild pigs to agriculture across their range, little quantitative research regarding timing of damage has been published. Similarly, although resource selection patterns of wild pigs have been reported (Spitz and Janeau, 1995; Thurfjell et al., 2009), the extent to which wild pig damage is correlated with preferred habitat attributes has largely been unexplored within their introduced range. Given the paucity of data on wild pig damage to agriculture within their introduced range, the objectives of this research were to identify the timing and extent of wild pig damage to corn and peanuts in central South Carolina, USA, and to model the influence of landscape habitat attributes and relative abundance of wild pigs on the presence and extent of damage. We hypothesized wild pig damage to these crops would follow caloric density of the crop fruit, and peak at planting and upon maturation for each crop. We also expected the presence and severity of wild pig damage would be positively associated with the proximity of fields to wetlands, forested areas, and other preferred habitat attributes, as well as pig abundance. Such data are needed to elucidate spatial and temporal dynamics associated with wild pig damage to crops to facilitate development of appropriate management strategies for minimizing impacts of wild pigs to agricultural producers.

\section{Methods}

\subsection{Study area}

We conducted crop damage surveys in Calhoun, Aiken, Bamberg, Colleton, and Hampton Counties, in the Southern Coastal Plain region of South Carolina, USA during the 2017 and 2018 growing seasons (Fig. 1). Calhoun County is in central South Carolina and bordered on the northeast by the Congaree River, adjacent to Congaree National Park. Aiken, Hampton and Bamberg Counties are located to the westsouthwest of Calhoun County, and the five counties together have a total area of $6238 \mathrm{~km}^{2}$, of which $2182 \mathrm{~km}^{2}$ was actively farmed. Areas of planted corn and peanuts for 2017 and 2018 by county are available in Table 1. Mean crop yield for the five counties over both years was $8094.8 \mathrm{~kg}$ of corn per ha and $4126.8 \mathrm{~kg}$ of peanuts per ha (NASS, 2018a; NASS, 2018b). The dominant forest type in the Southern Coastal Plain are loblolly (Pinus taeda Linnaeus)-shortleaf pine (Pinus echinate Miller), followed by oak (Quercus spp.)- sweetgum (Liquidambar styraciflua Linnaeus)-cypress (Taxodium distichum Richard), and oak-pine. Mean temperature for the growing season (March-November) was 20.9C in 2017 and 20.1C in 2018, compared with a typical mean temperature of 20.1C. Mean precipitation was $99.1 \mathrm{~mm}$ in 2017 and $125.0 \mathrm{~mm}$ in 2018, compared with a typical mean of $102.9 \mathrm{~mm}$ (SERCC, 2019).

Counties within our study area are overwhelmingly rural, with human population densities ranging from 6 (Calhoun County) to 58 (Aiken County) people per $\mathrm{km}^{2}$ (USDHUD, 2018). All five counties were identified by South Carolina Department of Natural Resources as moderate to high wild pig population regions, with the highest concentrations of pigs located along major waterways. Calhoun County also has some of the highest pig harvest numbers in the state (SCDNR, 2014).

\subsection{Crop damage sampling}

We selected fields in Calhoun County that were in proximity to Congaree National Park, in general areas where wild pigs were known to be present based on observations by USDA Wildlife Services (WS) personnel and agricultural producers in the area. Similarly, fields in Bamberg, Hampton, Colleton, and Aiken Counties were identified by county cooperative extension agents as having had pig damage in recent years or were in proximity to previously damaged fields. Some method of wild pig control (hunting, running with dogs, trapping) was conducted on all properties surveyed in this study, typically by local landowners; properties in Calhoun County were also managed by professional USDA/APHIS Wildlife Services biologists.

Using the default satellite basemap, we calculated field areas using ArcMap 10.1 (ESRI, Redlands, CA, USA). We then used a modified version of the crop damage walking survey methods described by Retamosa et al. (2008) to select and survey transects. We established two edge transects and 2-4 interior transects within each field depending on the total field area. Fields $<12$ ha in area had no interior transects, fields $12-24$ ha had two interior transects, and fields $>24$ ha had four interior transects. Once fields were selected for survey, we identified the two edges bordered by the largest area of forest using satellite imagery to establish edge transects. For instances where crop row orientation ran perpendicular to the selected edges, edge transects were set on the next most forested edge. Edge transects were established 3-12 rows from the field border using a random number generator, with the same value used for both edge transects in each field. We distributed all interior transects at equidistant intervals relative to the overall field width. We identified transect start, end, and navigation points (in the case of an irregular field shape) with a combination of marking paint and contractor flags. Transects within a field remained permanent throughout all surveys conducted within a growing season.

We began ground surveys 10-12 days after planting to allow for both plant emergence and opportunity for wild pig damage. As planting is heavily influenced by both local and seasonal weather patterns, initial 


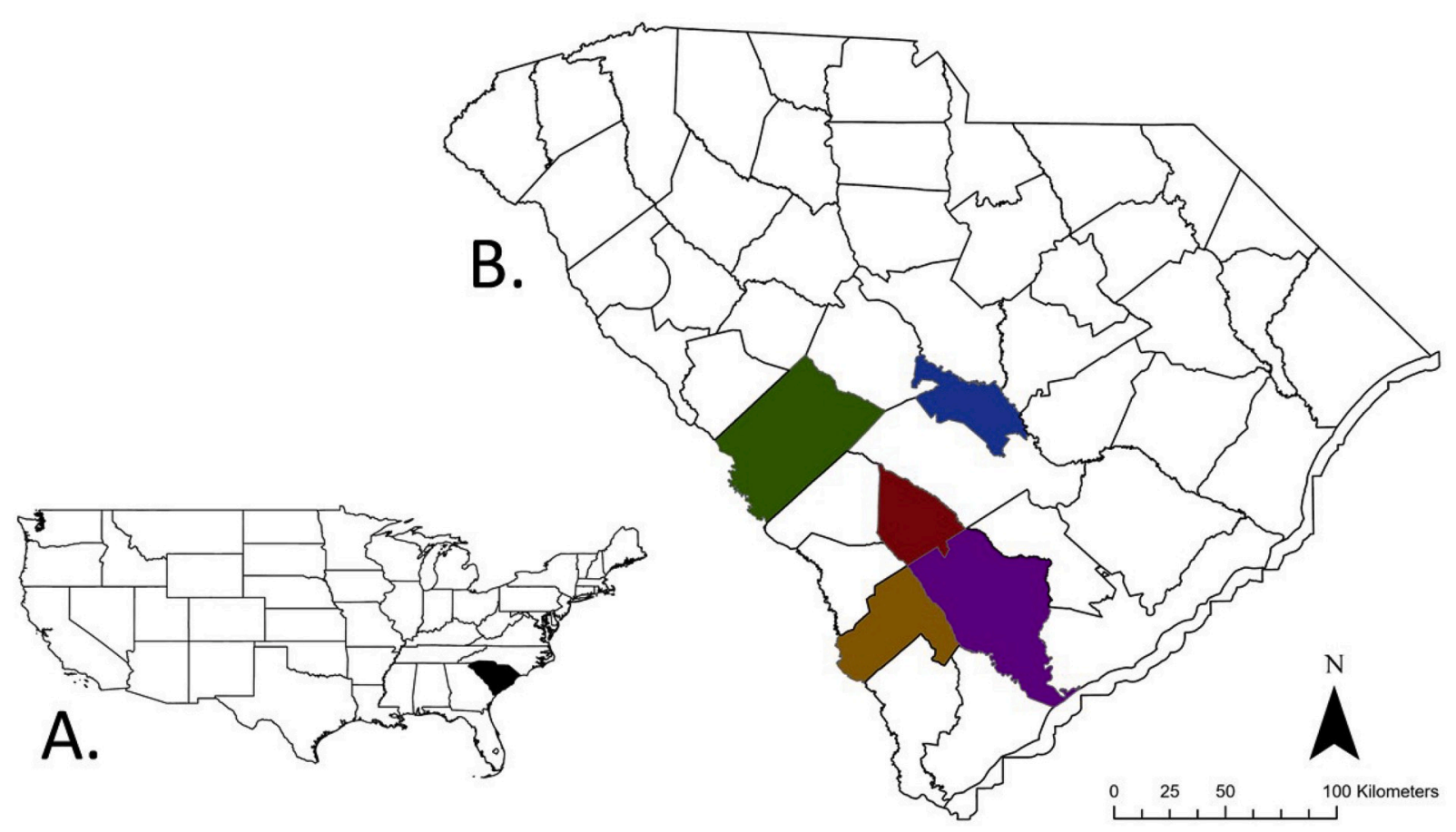

Fig. 1. Map showing (A.) the location of South Carolina within the United States and (B.) the five counties encompassing our surveyed fields (Aiken in green, Calhoun in blue, Bamberg in red, Colleton in purple, and Hampton in orange). (For interpretation of the references to colour in this figure legend, the reader is referred to the Web version of this article.)

Table 1

Planted area in hectares of the five counties in which our survey fields were located, showing corn (Zea mays) and peanuts (Arachis hypogaea) over the 2017 and 2018 growing seasons. A value of NA denotes missing information from the NASS reports.

\begin{tabular}{lllll}
\hline County & $\begin{array}{l}\text { Corn planted } \\
2017\end{array}$ & $\begin{array}{l}\text { Corn planted } \\
2018\end{array}$ & $\begin{array}{l}\text { Peanuts } \\
\text { planted 2017 }\end{array}$ & $\begin{array}{l}\text { Peanuts } \\
\text { planted 2018 }\end{array}$ \\
\hline Aiken & NA & 2267 & NA & NA \\
Bamberg & 2469 & 2793 & 2186 & 1336 \\
Calhoun & 3562 & NA & 4938 & 3278 \\
Colleton & 1781 & 1619 & 1579 & 1012 \\
Hampton & 2712 & 2348 & 3319 & 2631 \\
\hline
\end{tabular}

surveys were staggered across several weeks among sampled fields (March-April for corn and April-May for peanuts). We performed additional surveys at approximately 30-day intervals until harvest to capture the progression of damage relative to crop growth stage; we conducted four surveys for corn fields and five surveys for peanuts. Each survey coincided with a particular growth stage for each crop. For corn, the measured stages were emergence ( $~ 6$ days), 4th-6th leaf (V4-V6, $\sim 30$ days), silk (R1, $\sim 70$ days), and mature ( $~ 110$ days). For peanuts the measured stages were emergence (approximately 10 days), flowering (R1, approximately 30 days), peg development/pod development (R2/R3, approximately 60 days), beginning seed (R5, approximately 90 days), and mature plants turned to dry in the sun (turned/drying, approximately 120 days).

We limited damage assessment to three rows to the left and right of each transect row. We placed this limit to ensure damage could be detected and quantified in mature fields, and to set a maximum sampling effort in heavily damaged fields. At each damage location we recorded distance from the start of each transect using a measuring wheel, distance from the transect row, total number of plants damaged, and the species responsible for the damage. We identified any damage from wild pigs, white-tailed deer (Odocoileus virginiana Zimmermann), raccoons (Procyon lotor Linnaeus), birds, small mammals, and water (MacGowan et al., 2006). This damage included rooting, consumption of the seed or seedling, trampling, and feeding on individual ears. To ensure accuracy if damage patterns were not easily discernable, we used track and scat presence to help determine the causal species. We classified damage as unknown if we could not identify the source. Incidental trampling damage from deer, coyotes (Canis latrans Say), humans, vehicles, and irrigation pivots was excluded. In the case of severe water or animal damage where counting of individual plants was not feasible, we determined the number of damaged plants by measuring the length of each damaged section and dividing by the planting interval. To simplify data collection and analysis, we counted damage from all sources in terms of number of plants damaged, rather than parts of plants; half an ear missing from a stalk of corn was counted equal to a seedling destroyed by rooting. To maintain a constant measure through the peanut drying phase, we counted damage to the turned root systems at the same interval as the seed spacing. For example, if peanuts were planted at $5 \mathrm{~cm}$ intervals, we counted damage to exposed seeds within 5 $\mathrm{cm}$ as one plant. We marked all damaged plants or damaged field sections with spray paint to avoid double-counting damage across survey dates. The sowing density of the corn fields we surveyed was 54,300-91, 400 plants per hectare with a mean of 75,800 ; the density of peanut fields was $215,200-260,450$ plants per hectare with a mean of 236,200 . The sowing density for both crops varied due to the presence of irrigation, planting row width, and single or double row planting systems.

\subsection{Camera surveys}

To estimate relative abundance of wild pigs at surveyed fields, we set baited remote camera (Reconyx HC600 infrared; Reconyx, Holmen, WI, USA) traps adjacent to corn and peanut fields. During 2017 we conducted camera surveys in May and September (the May survey coincided with the R1 stage for corn and the V1 stage for peanuts; the September survey coincided with the silk/mature stage for corn and the R3 stage for peanuts). In 2018 we altered the timing of camera placement to coincide with the mature stage of each crop (July and October). In both years, cameras were placed on the two crop types simultaneously. We placed 
cameras adjacent to approximately half of the surveyed fields (15/29 corn fields and 24/41 peanut fields). We used damage counts from the first round of surveys to select fields to receive cameras, and attempted to distribute cameras across fields that were anticipated to vary in extent of wild pig damage. To maximize potential for pig detection, we scouted field edges for game trails or other sign and placed cameras on trails, wallows, and field roads. We placed 1-3 cameras per field depending on field size $>100 \mathrm{~m}$ apart, with 56 cameras placed in 2017 and 68 in 2018. We set cameras to take bursts of 3 photos triggered upon detection of motion, with a 3-min rest period between bursts. We affixed cameras to trees approximately $1 \mathrm{~m}$ off the ground and oriented southward. We baited each camera with $12 \mathrm{~kg}$ of corn, $\sim 2.5-5 \mathrm{~kg}$ of which was used to make a bait trail extending from the field edge, past the camera, and along the game trail into the woods. We set cameras for ten days each round, and rebaited them on day six.

We imported images from all cameras into the Colorado Parks and Wildlife Photo Warehouse for identification (Colorado Parks and Wildlife, Denver, CO, USA). All images without wild pigs were discarded. We examined the remaining pictures and quantified the total number of images with pigs for each field and the number of individual pigs present. We identified individual animals by pelage markings, scars, and group composition (Keiter et al., 2017).

\subsection{Landscape attributes}

For this study, we identified agricultural land, wetlands, and forest as the most salient land cover classes likely to influence wild pig damage to crops. We used the Multi-Resolution Land Characteristics National Land Cover Database (NLCD; Multi-Resolution Land Characteristics Consortium, U.S. Geological Survey, Sioux Falls, SD, USA) to identify these land cover types within the study area. The NLCD data is provided at a $30 \mathrm{~m}$ resolution, with land classified into 16 types. To determine the relative availability of these habitats proximal to surveyed fields, we quantified the amount (ha) of agricultural land, wetland, and forest habitat within a $1 \mathrm{~km}$ buffer from the edge of each field using ArcMap 10.1. For each field we also quantified field edge length, field area, distance to nearest water source, and percentage of field perimeter adjacent to paved roads (Table 2).

We delineated the length of edge for each field using a polygon vector in ArcMap. Field edges were identified using the default ArcMap satellite basemap. We used the South Carolina Department of Natural Resources GIS Data Clearinghouse (SCDNR, http://www.dnr.sc.gov/ GIS/gisdownload.html) to obtain hydrography quadrangles. Ephemeral water sources were censored from the layers, and we calculated the distance from the field edge to the nearest water source. To capture paved roads that might be slightly separated from a field edge, we applied a 20-m buffer to each edge and measured the proportion of each total field edge that was adjacent to paved roads.

\subsection{Statistical analyses}

Because we were specifically interested in modeling wild pig damage to corn and peanut crops, only damage by wild pigs was included in

Table 2

Landscape attributes used to model wild pig (Sus scrofa) damage to corn (Zea mays) and peanut (Arachis hypogaea) fields in South Carolina, USA.

\begin{tabular}{ll}
\hline Variables & Description \\
\hline Area & Area (ha) of field \\
P.Per & Percentage of paved field edge (20 m buffer) \\
W.Dist & Distance to nearest water source (m) \\
A.Buf & Area (ha) of agricultural land within $1 \mathrm{~km}$ buffer of field edge \\
Wet.Buf & Area (ha) of wetland and emergent wetland within $1 \mathrm{~km}$ buffer of field \\
& $\begin{array}{l}\text { edge } \\
\text { Evd.Buf }\end{array}$ \\
& $\begin{array}{l}\text { Area (ha) of forest (evergreen and hardwood) within } 1 \mathrm{~km} \text { buffer of field } \\
\text { edge }\end{array}$ \\
\hline
\end{tabular}

statistical models; damage by other species is presented in Figs. 1 and 3. We performed all analyses in RStudio (Version 0.98.507). We first examined the data for normality using the Shapiro-Wilk test and found them to be non-normally distributed; thus non-parametric tests were used for all analyses. To elucidate whether differences in the number of plants damaged existed between growth stages, we ran separate KruskalWallis $\mathrm{H}$ tests for each crop. We followed this with a pairwise Wilcoxon rank sum test to determine specific growth stages where differences in damage existed.

To evaluate whether the measured landscape attributes were important predictors of wild pig damage, we used logistic regression where fields were classified as damaged or not damaged by wild pigs. Prior to this analysis we ran a Spearman's rho correlation test on all combinations of landscape attributes to determine the presence of correlations between variables, and only variables with rho $<0.4$ were included in individual models.

We developed a suite of regression models for each crop type, and ranked all combinations of non-correlated field and landscape attribute variables using Akaike Information Criterion corrected for small sample size (AICc) (R package MuMIn). For peanuts we also developed a separate suite of candidate models that included relative pig abundance based on the number of individuals identified from remote camera images. We did not include estimates of pig abundance in models of corn damage due to low detection rates of pigs among the surveyed corn fields (see results). Models within $\Delta 2$ AICc of the top model were considered supported.

In addition to the damage/no damage models, we also evaluated the influence of the field and landscape attributes and pig abundance on the total number of damaged plants observed within each field. These data were over-dispersed, and thus we used a negative binomial regression and developed separate candidate models for corn and peanut fields that were ranked by AICc as described above (MASS R package). For these analyses, we censored all fields without damage from wild pigs.

\section{Results}

\subsection{Damage counts}

Over the two field seasons, we surveyed a total of 29 corn and 41 peanut fields. As farmers in South Carolina typically follow a three-year planting rotation, we placed cameras at different sites from 2017 to 2018. The area of surveyed fields across both years was 672.6 ha corn (mean $=21.44, \mathrm{SD}=19.73)$ and 734.7 ha peanuts $($ mean $=17.61, \mathrm{SD}=$

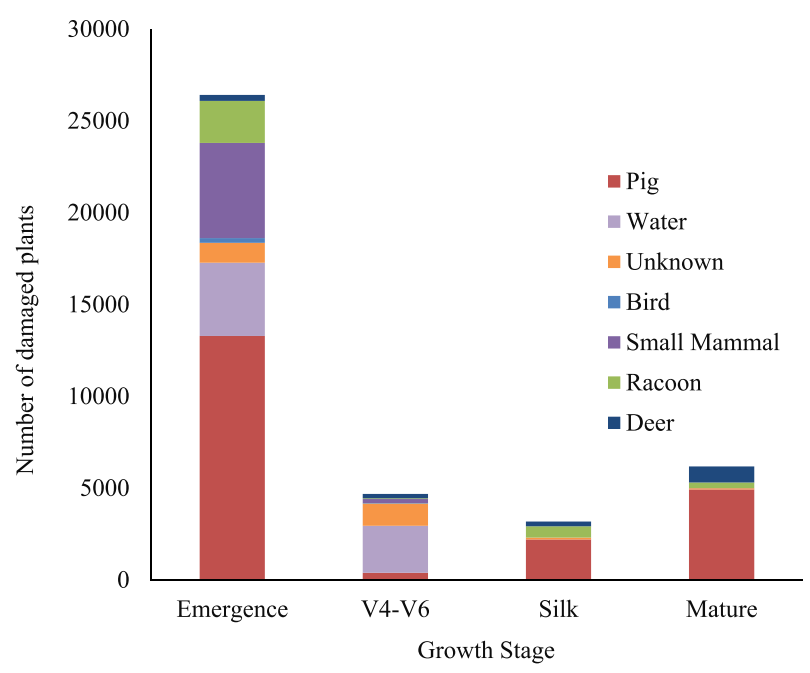

Fig. 2. Total number of damaged corn (Zea mays) plants detected within transects among plant developmental stages quantified across 29 corn fields surveyed in 2017 and 2018 in South Carolina, USA. 


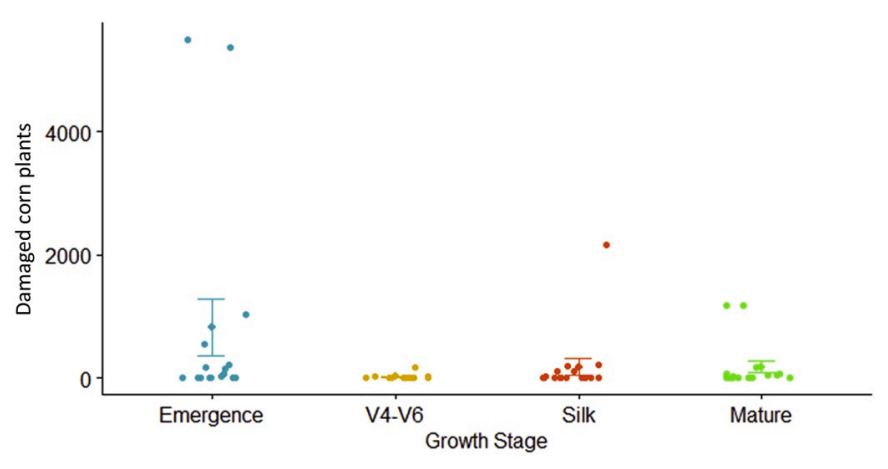

Fig. 3. Pairwise Wilcoxon test results for differences in wild pig (Sus scrofa) damage to corn (Zea mays) fields among growth stages in South Carolina, USA. This figure shows the V4-V6 stage differed in extent of damage compared to other growth stages.

16.66) for a total of 1415.9 ha. Of the 29 surveyed corn fields, 18 (62\%) had identifiable wild pig damage. Wild pigs, water, and small mammals were responsible for most recorded damage across all corn fields (Fig. 2). The number of plants damaged by wild pigs within the walked transects ranged from 0 to 6049 per corn field, with a total of 17,637 damaged plants between both years. Wild pigs accounted for $62.5 \%$ of measured wildlife damage. Of the 15 corn fields that had remote cameras, only 1 captured images of wild pigs. We did encounter the loss of four cameras on corn fields due to theft, destruction by prescription burning, and destruction by land clearance. Therefore, we did not include pig numbers in subsequent models for corn. One corn field was surveyed both years; for this field we averaged wild pig damage measured between years and reported it as single survey in the models. The KruskalWallis test revealed significant differences in wild pig damage among corn growth stages $\left(\chi^{2}=8.50, \mathrm{df}=3, P=0.04\right)$. The most extensive wild pig damage to corn occurred shortly after planting, followed by the silk (R1) and mature stages, although only the comparison between the emergence and V4-V6 stages differed based on the pairwise Wilcoxon test (Fig. 3).

We identified wild pig damage in 16 of 41 (39\%) surveyed peanut fields. The majority of wildlife damage to peanuts was attributed to wild pigs, with $<10 \%$ of wildlife damage attributed to all other species combined (Fig. 4). Water damage was also a significant source of damage to plants within surveyed peanut fields, accounting for $25 \%$ of measured damage ( $n=6637$ plants for both survey years combined). Similar to corn, peanut damage by wild pigs ranged from 0 to 6720 plants among fields, with a sum of 18,903 damaged plants across all fields within our surveyed transects. We placed cameras at 24 of these fields, and detected pigs at 8 of them. We lost three cameras due to theft

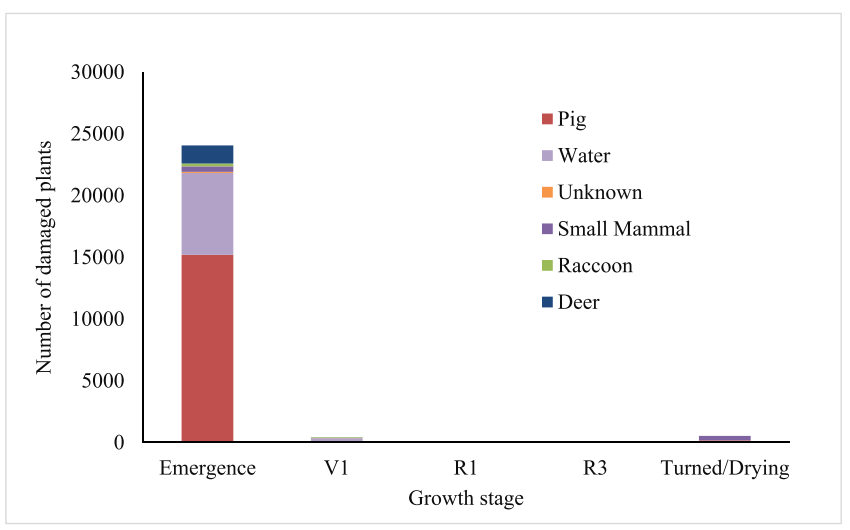

Fig. 4. Total damaged peanut (Arachis hypogaea) plants detected within transects among plant developmental stages quantified across 41 peanut fields surveyed in 2017 and 2018 in South Carolina, USA. and land clearance. Wild pig damage to peanuts differed among growth stages $\left(\chi^{2}=48.06, \mathrm{df}=4, P<0.001\right)$, with $>97 \%$ of pig damage occurring in the emergence growth stage. The pairwise Wilcoxon test indicated a significant difference in damage between emergence and all other stages $(P<0.001$, Fig. 5).

\subsection{Landscape attributes}

Among the binomial regression models for evaluating the influence of landscape attributes on whether a corn field was damaged by wild pigs, there were two supported models, with the top model consisting of the agricultural buffer, paved perimeter, and wetland buffer variables ( $\omega=0.45$; Table 3$)$. The second supported model included the same variables with the addition of the forest buffer $\left(\omega=0.25, \Delta \mathrm{AIC}_{\mathrm{c}}=1.18\right)$. Both paved perimeter and agricultural buffers were negatively associated with pig damage, while wetland and forest buffers were positively associated. The wetland buffer appeared in the 9 top models.

The binomial regression models of peanut damage without camera data yielded five supported models, although the weight of these models was relatively weak. The top model included only the forest buffer, which was included in all supported models ( $\omega=0.17$; Table 4). Paved perimeter, agricultural buffer, and wetland buffer also were included in supported models. Similar to the models of corn damage, wild pig damage to peanuts was positively associated with forest and wetland buffers, and negatively associated with paved perimeter. The forest buffer was the strongest predictor among the measured landscape attributes, appearing in the top 9 models. The binomial regression models including the number of wild pigs detected on camera resulted in six supported models, with pig abundance included in all supported models. However, inclusion of pig abundance did not appear to substantially improve the predictive power based on model weights (Table 5).

After removing undamaged fields, the negative binomial models exploring the influence of the measured habitat attributes on the number of corn plants damaged by wild pigs produced a single supported model positively associated with field area alone $(\omega=0.41)$. Due to the appearance of two heavily damaged fields as outliers, we re-ran the regression after removing them. There was no marked change in the binomial regression for undamaged corn fields, although removal of these outliers resulted in a single supported model positively associated with the amount of wetland buffer $(\omega=0.45)$ in our negative binomial models using only damaged fields. There were five supported models for the analysis of wild pig damage to peanuts, excluding the number of wild pigs detected on cameras (Table 6). These models each contained only one variable. However, when we included the number of wild pigs detected at crop fields within the models, a single model containing only the number of observed pigs was supported $(\omega=0.60)$.

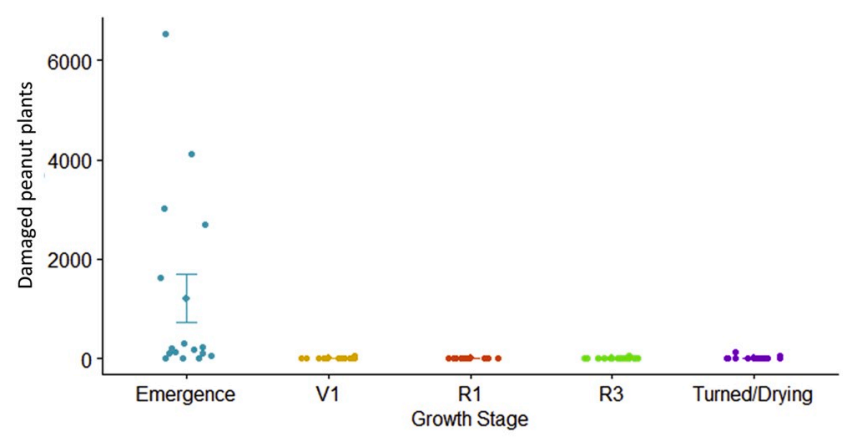

Fig. 5. Pairwise Wilcoxon test results for differences in wild pig (Sus scrofa) damage to peanut (Arachis hypogaea) fields among growth stages in South Carolina, USA. This figure shows emergence stage differed in extent of damage compared to all other growth stages. 
Table 3

Supported binomial regression models of wild pig (Sus scrofa) damage to corn (Zea mays) fields as a function of habitat attributes in South Carolina, USA with associated $\mathrm{AIC}_{\mathrm{c},} \Delta \mathrm{AIC}_{\mathrm{c}}$, and model weight $(\omega)$. A $(+)$ or $(-)$ before each variable indicates a positive or negative association respectively.

\begin{tabular}{llll}
\hline Model & $\mathrm{AIC}_{\mathrm{c}}$ & $\Delta \mathrm{AIC}_{\mathrm{c}}$ & $\omega$ \\
\hline (-)A.Buf $+(-)$ P.Per $+(+)$ Wet.Buf & 26.49 & 0.00 & 0.45 \\
(-)A.Buf $+(+)$ Evd.Buf $+(-)$ P.Per $+(+)$ Wet.Buf & 27.66 & 1.18 & 0.25 \\
\hline
\end{tabular}

A.Buf $=$ agricultural area within $1 \mathrm{~km}$ buffer.

Area $=$ field area.

P.Per $=$ paved perimeter.

W.Dist $=$ distance to water.

Wet.Buf $=$ wetland area within $1 \mathrm{~km}$ buffer.

Evd.Buf $=$ forested area within $1 \mathrm{~km}$ buffer.

Table 4

Supported binomial regression models of wild pig (Sus scrofa) damage to peanut (Arachis hypogaea) fields as a function of habitat attributes in South Carolina, USA with associated $\mathrm{AIC}_{\mathrm{c}}, \Delta \mathrm{AIC}_{\mathrm{c}}$, and model weight $(\omega)$. A $(+)$ or $(-)$ before each variable indicates a positive or negative association respectively.

\begin{tabular}{llll}
\hline Model & $\mathrm{AIC}_{\mathrm{c}}$ & $\Delta \mathrm{AIC}_{\mathrm{c}}$ & $\omega$ \\
\hline (+)Evd.Buf & 53.04 & 0.00 & 0.17 \\
(+)Evd.Buf $+(-)$ P.Per & 54.09 & 1.04 & 0.10 \\
(+)Evd.Buf $+(-)$ P.Per $+(+)$ Area & 54.26 & 1.21 & 0.09 \\
(+)A.Buf $+(+)$ Evd.Buf & 54.74 & 1.70 & 0.07 \\
\hline
\end{tabular}

A.Buf $=$ agricultural area within $1 \mathrm{~km}$ buffer.

Area $=$ field area.

P.Per $=$ paved perimeter.

W.Dist $=$ distance to water

Wet.Buf = wetland area within $1 \mathrm{~km}$ buffer.

Evd.Buf $=$ forested area within $1 \mathrm{~km}$ buffer.

Table 5

Supported binomial regression models of wild pig (Sus scrofa) damage to peanut (Arachis hypogaea) fields as a function of habitat attributes and the number of pigs detected on remote cameras in South Carolina, USA with associated $\mathrm{AIC}_{\mathrm{c}}$, $\Delta \mathrm{AIC}_{\mathrm{c}}$, and model weight $(\omega)$. A $(+)$ or $(-)$ before each variable indicates a positive or negative association respectively.

\begin{tabular}{llll}
\hline Model & $\mathrm{AIC}_{\mathrm{c}}$ & $\Delta \mathrm{AIC}_{\mathrm{c}}$ & $\omega$ \\
\hline (+)Evd.Buf + (+)P.Num & 34.84 & 0.00 & 0.14 \\
(+)Evd.Buf + (-)W.Dist + (+)P.Num & 34.93 & 0.09 & 0.13 \\
(+)Evd.buf + (+)Wet.Buf + (+)P.Num & 35.23 & 0.39 & 0.11 \\
(+)P.Num & 35.72 & 0.88 & 0.09 \\
(+)Evd.Buf + (-)P.Per + (+)P.Num & 36.45 & 1.61 & 0.06 \\
(-)P.Per + (+)P.Num & 36.80 & 1.97 & 0.05 \\
\hline
\end{tabular}

A.Buf $=$ agricultural area within $1 \mathrm{~km}$ buffer.

Area $=$ field area.

P.Per $=$ paved perimeter.

W.Dist $=$ distance to water.

Wet.Buf $=$ wetland area within $1 \mathrm{~km}$ buffer.

Evd.Buf $=$ forested area within $1 \mathrm{~km}$ buffer.

P.Num $=$ number of wild pigs detected on camera.

\section{Discussion}

Wild pigs have one of the widest distributions of any terrestrial mammal on the planet, with the global distribution of both native and introduced populations spanning more than 100 countries (Barrios-Garcia and Ballari, 2012; Ballari and Barrios-Garcia, 2014; Herrero et al., 2007). As a result, agricultural damage by wild pigs is a global issue and thus the ability to determine factors influencing the timing and location of damage is crucial to mitigating conflicts between humans and wild pigs (Bleier et al., 2017). Across fields surveyed in this study, the majority of damage by wildlife was attributed to wild pigs, although wild pig damage was highly variable in both space and time. Using
Table 6

Supported negative binomial regression models of wild pig (Sus scrofa) damage to peanut (Arachis hypogaea) fields as a function of habitat attributes in South Carolina, USA with associated $\mathrm{AIC}_{\mathrm{c}}, \Delta \mathrm{AIC}_{\mathrm{c}}$, and $\omega . \mathrm{A}(+)$ or $(-)$ before each variable indicates a positive or negative association respectively.

\begin{tabular}{llll}
\hline Model & AICc & $\Delta$ AIC $c$ & $\omega$ \\
\hline (+)Area & 255.19 & 0.00 & 0.24 \\
(+)Evd.Buf & 256.67 & 1.49 & 0.11 \\
(+)A.Buf & 256.86 & 1.67 & 0.10 \\
(-)Wet.Buf & 256.96 & 1.78 & 0.1 \\
(-)P.Per & 257.07 & 1.88 & 0.09 \\
\hline
\end{tabular}

A.Buf = agricultural area within $1 \mathrm{~km}$ buffer.

Area $=$ field area.

P.Per $=$ paved perimeter.

W.Dist $=$ distance to water.

Wet.Buf $=$ wetland area within $1 \mathrm{~km}$ buffer.

Evd.Buf $=$ forested area within $1 \mathrm{~km}$ buffer.

yearlong averaged national prices, we determined the total value of corn and peanuts damaged by wild pigs in our surveyed fields for both years combined was $\$ 1362$ and $\$ 1031$ respectively. Though this number may appear low given the detection of wild pig damage in more than 30 fields, our survey transects examined $<10 \%$ of total field areas.

Our results suggest wild pig damage to corn and peanut crops is primarily concentrated during specific growth stages, with the majority of damage occurring from planting up to the V4 stage for corn and up to the V1 stage for peanuts, although damage to corn fields also was extensive following the development of ears. These findings are consistent with anecdotal reports from agricultural producers and follow similar trends in damage to corn by wild pigs and red deer (Cervus elaphus Linnaeus) in Europe (Bleier et al., 2017), as well as raccoons and white-tailed deer in the U.S. (Humberg et al., 2007). Given the aggregated timing of most wild pig damage to corn and peanut crops, our data suggest targeted management of wild pigs may be most effective at reducing damage when conducted immediately prior to planting.

Although the extent of wild pig damage to corn and peanut fields was most pronounced shortly after planting, damage to corn was more variable throughout the growing season. Specifically, damage to corn fields decreased substantially after the emergence phase, with little damage observed prior to the milk stage. This is likely due to the limited calories associated with emergent seedlings compared to calorically dense seeds (Sassenrath et al., 2014). However, we observed substantial damage by wild pigs as the ears transitioned to the milk stage, when sugars are remobilized from the stem to the kernels (Setter and Meller, 1984). In fact, we observed the greatest amount of damage by wild pigs during this stage for five (of 18 damaged fields; $28 \%$ ) of the surveyed fields. Extensive damage to corn by wild pigs continued through the mature phase, likely due to the high caloric density of drying ears (Bleier et al., 2017; Keuling and Stier, 2010; Schley et al., 2008). These findings support research investigating wild boar damage to a wide variety of other crop types in Europe, which found farmers reported the most extensive damage after planting and shortly prior to harvest (Schley et al., 2008).

The timing of damage to peanuts was more surprising, as $>97.0 \%$ of all damage occurred during the emergence stage. We did not record any wild pig damage to peanuts during the peg/pod development stage, and the flowering, seeding, and mature plants accounted for $<3.0 \%$ of all measured damage. Upon development, peanuts contain too much moisture for storage and rows of plants are mechanically turned over just prior to harvest to dry the exposed seeds in the sun and air. Large concentrations of drying, mature peanuts offer a nutritionally appealing resource because of their high protein content, and thus we anticipated extensive damage to peanuts during this stage by wild pigs (Ditchkoff and Mayer, 2009). However, unlike mature corn, turned and drying peanuts offer little vertical cover $(\sim 20 \mathrm{~cm})$, and wild pigs may limit use of peanut fields during this period to minimize risks of predation (i.e. 
harvest by hunters). Indeed, the importance of cover as a factor in wild pig foraging behavior has been observed from GPS-collared animals in North America and Europe, even within agricultural areas (DEFRA, 2004; Wilber et al., 2020). This avoidance may be compounded in areas where hunting of wild pigs overlaps with crop availability. Thurfjell et al. (2013) found the presence of hunters, even those hunting non-pig species, changed the habitat use and movement patterns of wild boar in Sweden, resulting in less time spent outside dense cover and an overall reduction in movement. Within our study area wild pigs could be harvested year-round during both day and night on registered private land using thermal or night vision optics, increasing the vulnerability of wild pigs foraging in fields with limited cover. Deer hunters in South Carolina also are able to incidentally harvest wild pigs, and thus the presence of hunting pressure during the drying period (September-October) coupled with the lack of cover may alter wild pig movements and use of peanut fields during this time. Limited depredation of peanuts also may have been influenced by the timing of hard mast availability, a preferred food resource of wild pigs (Fournier-Chambrillon et al., 1995; Massei et al., 1996), which coincides with the maturation of peanut crops in our study area.

The binomial models evaluating the influence of landscape attributes on the presence and extent of wild pig damage suggested several attributes known to influence wild pig movements were important predictors of damage. In particular, the amount of forest land surrounding crop fields and the availability of wetlands were positively associated with wild pig damage, whereas the amount of agriculture adjacent to sampled fields and the proximity of paved roads were negatively associated with damage. Fields embedded within a predominantly agricultural matrix offer limited cover for wild pigs, and wild boar have been found to limit movement between fields when there was little cover (Thurfjell et al., 2009). Similarly, paved roads represent an important source of mortality for wild pigs and wild boar (Colino-Rabanal et al., 2012, Beasley et al., 2014; Saenz-de-Santa-Maria and Telleria, 2015), and individuals often avoid crossing paved roads and high-traffic areas (Wyckoff et al., 2012, Thurfjell et al., 2015).

The association between wild pig damage and the availability of forest and wetland habitats supports previous research on wild boar that observed increased crop use in fields adjacent to forested and edge habitats (Gerard et al., 1991; Herrero et al., 2006, Wilber et al., 2020), as well as rivers (Amici et al., 2012). Wild pig movements are often concentrated within forested areas, particularly those dominated by bottomland hardwoods, as these areas provide access to nutritional hard mast as well as dense cover (Singer et al., 1981; Hayes et al., 2009). Wild pigs preferentially select hard mast over agricultural nutrition sources, and will often seasonally feed on mast extensively during abundant mast years (Fournier-Chambrillon et al., 1995; Massei et al., 1996). Additionally, the importance of wetlands in predicting wild pig damage is unsurprising as pigs are poor thermoregulators, and often concentrate movements near wetlands and riparian habitats due to the availability of foraging and wallowing habitats (Choquenot et al., 1996; Eckert et al., 2019). Indeed, the area of wetlands proximal to corn fields was a positive predictor of fields where damage occurred, and upon removing the two most heavily damaged fields from our analysis the area of adjacent wetlands also was the most important driver of the extent of wild pig damage within fields. While we have no appropriate reason to censor these fields, this result suggests these fields may have been driving our overall model results. The abundance results from our remote cameras became the single greatest predictor of the extent of wild pig damage to peanut fields. This method of data collection is far less demanding compared to walked surveys in both time and required skill, and may be employed by individual landowners on a smaller scale. Though we did lose several cameras on corn fields with high amounts of wild pig damage, we were not able to determine why the detection of wild pigs was so low. We may have simply selected incorrect game trails on some fields, or placed cameras in incorrect areas given the location of wild pig damage.
Our results illustrate the importance of early wild pig detection in determining where control efforts should occur. In particular, if wild pig populations around corn and peanut fields can be even temporarily disrupted or eliminated by professional managers or landowners immediately prior to planting, damage risks to those crops likely can be greatly reduced. Indeed, a survey of damage at the emergence stage reported that of 46 surveyed fields, none of the 14 subjected to wild pig removal by professional trappers were damaged by wild pigs (Engeman et al., 2018); fields receiving protection were all damaged in previous years, thus the absence of damage likely was a direct result of management efforts. Further, although the methods we used for measuring damage are time consuming and likely not applicable at large spatial scales, especially by private landowners, the results suggest several landscape attributes known to influence wild pig movements can be important predictors of the likelihood of wild pig damage and thus may serve as useful predictors for investigating areas of potential wild pig control. Use of trail cameras to elucidate the number of pigs inhabiting forest areas adjacent to crop fields also may serve as a useful predictor of the potential extent of wild pig damage anticipated within a field, data that can further be used to prioritize and target management efforts within affected areas. However, given the number of damaged fields where no pigs were detected on camera in our study, a larger distribution and longer duration of camera deployment may be needed to accurately estimate the number of wild pigs potentially utilizing crop fields.

\section{Declaration of competing interest}

The authors declare that they have no known competing financial interests or personal relationships that could have appeared to influence the work reported in this paper.

\section{CRediT authorship contribution statement}

C.M. Boyce: Conceptualization, Methodology, Software, Formal analysis, Investigation, Data curation, Writing - original draft, Writing review \& editing, Visualization. K.C. VerCauteren: Conceptualization, Methodology, Resources, Writing - original draft, Writing - review \& editing, Supervision, Project administration, Funding acquisition. J.C. Beasley: Conceptualization, Methodology, Formal analysis, Resources, Writing - original draft, Writing - review \& editing, Supervision, Project administration, Funding acquisition.

\section{Acknowledgements}

Mention of commercial products or companies does not represent an endorsement by the U.S. Government. The findings and conclusions in this preliminary publication have not been formally disseminated by the US Department of Agriculture and should not be construed to represent any Agency determination or policy. This research was supported by the intramural research program of the U.S. Department of Agriculture, Animal and Plant Health Inspection Service, Wildlife Services, as well as the US Department of Energy under Award No. DE-EM0004391 to the UGA Research Foundation. We thank Clemson University Cooperative Extension agents for their help in coordinating our efforts with landowners. We also thank the landowners who volunteered their land and time, without which this project would not have been possible. Additional thanks to Dr. M. Mengak of the University of Georgia for his assistance and comments on drafts of this manuscript.

\section{References}

Amici, A., Serrani, F., Rossi, C.M., Primi, R., 2012. Increase in crop damage caused by wild boar (Sus scrofa L.): the "refuge effect". Agronomy for Sustainable Development 32 (3), 683-692.

Anderson, A., Slootmaker, C., Harper, E., Holderieath, J., 2016. Economic estimates of feral swine damage and control in 11 US states. Crop Protect. 89, 89-94. 
Ballari, S.A., Barrios-Garcia, M.N., 2014. A review of wild boar Sus scrofa diet and factors affecting food selection in native and introduced ranges. Mamm Rev. 44, 2.

Barrios-Garcia, M.N., Ballari, S.A., 2012. Impact of wild boar (Sus scrofa) in its introduced and native range: a review. Biol. Invasions 14 (11), 2283-2300.

Bevins, S.N., Pedersen, K., Lutman, M.W., Gidlewski, T., Deliberto, T.J., 2014. Consequences associated with the recent range expansion of nonnative feral swine. Bioscience 64, 291-299.

Beasley, J.C., Ditchkoff, S.S., Mayer, J.J., Smith, M.D., VerCauteren, K.C., 2018. Research priorities for managing invasive wild pigs in North America. Journal of Wildlife Management 82 (4), 674-681.

Beasley, J.C., Grazia, T.E., Johns, P.E., Mayer, J.J., 2014. Habitats associated with vehicle collisions with wild pigs. Wildl. Res. 40 (8), 654-660.

Bleier, N., Kovacs, I., Schally, G., Szemethy, L., Csanyi, S., 2017. Spatial and temporal characteristics of the damage caused by wild ungulates in maize (Zea mays L.) crops. Int. J. Pest Manag. 63 (1), 92-100.

Cai, J., Jiang, Z., Zeng, Y., Li, C., Bravery, B.D., 2008. Factors affecting crop damage by wild boar and methods of mitigation in a giant panda reserve. Eur. J. Wildl. Res. 54, 723-728.

Chiyo, P.I., Cochrane, E.P., Naughton, L., Basuta, G.I., 2005. Temporal patterns of crop raiding by elephants: a response to changes in forage quality or crop availability? Afr. J. Ecol. 43 (1), 48-55.

Choquenot, D., McIlroy, J., Korn, T., 1996. Managing vertebrate pests: feral pigs. Bureau of Resource Sciences, Australian Government Publishing Service, Canberra.

Colino-Rabanal, V.J., Bosch, J., Munoz, M.J., Peris, S.J., 2012. Influence of new irrigated croplands on wild boar (Sus scrofa) road kills in NW Spain. Anim. Biodivers. Conserv. 35 (2), 247-252.

DEFRA, 2004. The Ecology and Management of Wild Boar in Southern England (Report No. VC0325). London, UK. Department for Environment, Food and Rural Affairs.

DeVault, T.L., Beasley, J.C., Humberg, L.A., MacGowan, B.J., Retamosa, M.I., Rhodes, O. E., 2007. Intrafield patterns of wildlife damage to corn and soybeans in northern Indiana. Hum. Wildl. Conf. 1 (2), 205-213.

Ditchkoff, S.S., Mayer, J.J., 2009. Biology of wild pigs: wild pig food habits. In: Mayer, J. J., Brisbin, I.L. (Eds.), Wild Pigs, Biology, Damage, Control Techniques and Management. Savannah River National Laboratory, Aiken, SC, USA, pp. 111-143, 2009.

Eckert, K.D., Keiter, D.A., Beasley, J.C., 2019. Animal visitation to wild pig (Sus scrofa) wallows and implications for disease transmission. Journal of Wildlife Diseases 55 (2), 488-493.

Engeman, R.M., Terry, J., Gruver, K.S., 2018. Prevalence and amount of feral swine damage to three row crops at planting. Crop Protection 112, 252-256.

Fournier-Chambrillon, C., Maillard, D., Fournier, P., 1995. Diet of the wild boar (Sus scrofa L.) inhabiting the Montpellier Garrigue. Conference. In: Proceedings of 2nd International symposium on Wild Boar (Sus scrofa) and on order Suiformes, 3, pp. 174-179.

Garrison, R.L., Lewis, J.C., 1987. Effects of browsing by white-tailed deer on yields of soybeans. Wildl. Soc. Bull. 15 (4), 555-559.

Geisser, H., Reyer, H., 2005. The influence of food and temperature on population density of wild boar Sus scrofa in the Thurgau (Switzerland). J. Zool. 267, 89-96.

Gerard, J., Cargnelutti, B., Spitz, F., Valet, G., Sardin, T., 1991. Habitat use of wild boar in a French agroecosystem from late winter to early summer. Acta Theriologica 36 (1-2), 112-129.

Gimenez-Anaya, A., Herrero, J., Rosell, C., Couto, S., Garcia-Serrano, A., 2008. Food habits of wild boars (Sus Scrofa) in a mediterranean coastal wetland. Wetlands 28 , 197-203.

Gipson, P.S., Hlavachick, B., Berger, T., 1998. Range expansion by wild hogs across the Central United States. Wildl. Soc. Bull. 26 (2), 279-286.

Gross, E.M., Lahkar, B.P., Subedi, N., Nyirenda, V.R., Lichtenfield, L.L., Jakoby, O., 2018. Seasonality, crop type and crop phenology influence damage by wildlife herbivores in Africa and Asia. Biodivers. Conserv. 27 (8), 2029-2050.

Hayes, R., Riffell, S., Minnis, R., Holder, B., 2009. Survival and habitat use of feral hogs in Mississippi. SE. Nat. 8 (3), 411-426.

Herrero, J., Garcia-Serrano, A., Couto, S., Ortuno, V., 2006. Diet of wild boar Sus Scrofa L. and crop damage in an intensive agroecosystem. Eur. J. Wildl. Res. 52 (4), 245-250.

Herrero, J., Giannatos, G., Kranz, A., Conroy, J., 2007. Sus scrofa. The IUCN Red List of Threatened Species 2007 e.T41775A10562008. Downloaded on 22 April 2019.

Humberg, L.A., DeVault, T.L., MacGowan, B.J., Beasley, J.C., Rhodes Jr., O.E., 2007. Crop depredation by wildlife in northcentral Indiana. In: Stewart, A. (Ed.), The Proceedings of the Ninth National Wild Turkey Symposium. Grand Rapids, Michigan, pp. 199-205.

Keiter, D.A., Davis, A.J., Rhodes, O.E., Cunningham, F.L., Kilgo, J.C., Pepin, K.M., Beasley, J.C., 2017. Effects of scale movement, detection probability, and true population density on common methods of estimating population density. Sci. Rep. 7, 9446.

Keuling, O., Stier, N., 2010. How endangered in the maize? Movement pattern of wild boar in autumn. In: Book of Abstracts 8th International Symposium on Wild Boar and Other Suids. Food and Environment Research Agency, York (England), p. 60.

Lewis, J.S., Corn, J.L., Mayer, J.J., Jordan, T.R., Farnsworth, M.L., Burdett, C.L., VerCauteren, K.C., Sweeny, S.J., Miller, R.S., 2019. Historical, current, and potentia population size estimates of invasive wild pigs (Sus scrofa) in the United States. Biol. Invasions 21, 2373-2384.

Lombardini, M., Meriggi, A., Fozzi, A., 2017. Factors influencing wild boar damage to agricultural crops in Sardinia (Italy). Curr. Zool. 63 (5), 507-514.

MacGowan, B.J., Humberg, L.A., Beasley, J.C., DeVault, T.L., Retamosa, M.I., Rhodes, O. E., 2006. Corn and Soybean Crop Depredation by Wildlife. Purdue University Extension, FNR-265-W.
Massei, G., Genov, P.V., 2004. The environmental impact of wild boar. Galemys 16, $135-145$.

Massei, G., Genov, P.V., Staines, B.W., 1996. Diet, food availability and reproduction of wild boar in a Mediterranean coastal area. Acta Theol. 41 (3), 3097-3320.

Massei, G., Kindberg, J., Licoppe, A., Gacic, D., Sprem, N., Kamler, J., Baubet, E., Hohmann, U., Monaco, A., Ozolins, J., Cellina, S., Podgorski, T., Fonseca, C., Markov, N., Pokorny, B., Rosell, C., Nahlik, A., 2014. Wild boar populations up, number of hunters down? A review of trends and implications for Europe. Pest Manag. Sci. 71 (4), 492-500.

Mayer, J.J., Beasley, J.C., 2018. Wild pigs. In: Beasley, J.C., Witmer, G.W. (Eds.), Ecology and Management of Terrestrial Vertebrate Invasive Species in the United States. W.C. Pitt. CRC Press, Boca Raton, FL, USA.

Mayer, J.J., Brisbin, I.L., 2009. Wild Pigs: Biology, Damage, Control Techniques and Management. Savannah River National Laboratory, Aiken, South Carolina. SRNL-RP2009-00869.

Morelle, K., Podgorski, T., Prevot, C., Keuling, O., Lehaire, F., Lejeune, P., 2015. Towards understanding wild boar Sus scrofa movement: a synthetic movement ecology approach. Mamm Rev. 45, 15-29.

NASS, 2018. South Carolina county estimates: peanuts 2017-2018. U. S. Dep. Agric. Nat. Agric. Stat. Serv. Accessed December 2018 https://www.nass.usda.gov/Statistics _by_State/South_Carolina/Publications/County_Estimates/2018/SCPeanut2018.pdf.

NASS, 2018. South Carolina county estimates: corn 2017-2018. U. S. Dep. Agric. Nat. Agric. Stat. Serv. Accessed December 2018 https://www.nass.usda.gov/Statistics_ by_State/South_Carolina/Publications/County_Estimates/index.php.

Palacio, S., Bueno, C.G., Azorín, J., Maestro, M., Gómez-García, D., 2013. Wild-boar disturbance increases nutrient and C stores of geophytes in subalpine grasslands. Am. J. Bot. 100 (9), 1790-1799.

Retamosa, M.I., Humberg, L.A., Beasley, J.C., Rhodes, O.E., 2008. Modeling wildlife damage to crops in northern Indiana. Hum. Wildl. Conf. 2 (2), 225-239.

Saenz-de-Santa-Maria, A., Telleria, J.L., 2015. Wildlife-vehicle collisions in Spain. European Journal of Wildlife 61 (3), 399-406.

Saez-Royuela, C., Telleria, J.L., 1986. The increased population of the wild boar (Sus scrofa L.) in Europe. Mamm Rev. 16 (2), 97-101.

Sassenrath, G.F., Broome, J.H., Corbitt, J., Younes, S.T., Stover, M., Schneider, J.M., Steele, M., 2014. Assessing the energy production potential of Mississippi crops and crop residue using adiabatic bomb calorimetry. J. Miss. Acad. Sci. 59 (3-4), 396-407.

SERCC, 2019. Monthly and seasonal climate information. Southeast Reg. Clim. Center. Accessed January 2020, University of North Carolina Chapel Hill. https://sercc.com/ climateinfo/monthly_seasonal.

Setter, T.L., Meller, V.H., 1984. Reserve carbohydrate in maize stem. Plant Physiol. 75, $717-722$.

SCDNR, 2014. Feral Hog - Harvest Information. South Carolina Department of Natural Resources. Accessed February 2019. http://www.dnr.sc.gov/wildlife/hog/harvest. html.

Schley, L., Dufrene, M., Krier, A., 2008. Patterns of crop damage by wild boar (Sus scrofa) in Luxembourg over a 10-year period. Eur. J. Wildl. Res. 54, 589-599.

Schley, L., Roper, T., 2003. Diet of wild boar Sus Scrofa in Western Europe, with particular reference to consumption of agricultural crops. Mamm Rev. 33 (1), 43-56.

Singer, F.J., Otto, D.E., Tipton, A.R., Hable, C.P., 1981. Home ranges, movements, and habitat use of European wild boar in Tennessee. J. Wildl. Manag. 45 (2), 343-353.

Spear, D., Chown, S.L., 2009. Non-indigenous ungulates as a threat to biodiversity. J. Zool. 279 (1), 1-17.

Spitz, F., Janeau, G., 1995. Daily selection of habitat in wild boar (Sus scrofa). J. Zool. 237, 423-434.

Snow, N.P., Jarzyna, M.A., VerCauteren, K.C., 2017. Interpreting and predicting the spread of invasive wild pigs. J. Appl. Ecol. 54, 2022-2032.

Tabak, M.A., Piaggio, A.J., Miller, R.S., Sweitzer, R.A., Ernest, H.B., 2017. Anthropogenic factors predict movement of an invasive species. Ecosphere 8 (6).

Thurfjell, H., Ball, J.P., Ahlen, P., Kornacher, P., Dettki, H., Sjoberg, K., 2009. Habitat use and spatial patterns of wild boar Sus scrofa (L.): agricultural fields and edges. Eur. J. Wildl. Res. 55 (5), 517-523.

Thurfjell, H., Spong, G., Ericsson, G., 2013. Effects of hunting on wild boar Sus scrofa behavior. Wildl. Biol. 19, 87-93.

Thurfjell, H., Spong, G., Olsson, M., Ericsson, G., 2015. Avoidance of high traffic levels results in lower risk of wild boar-vehicle accidents. Landscape and Urban Planning 133, 98-104.

United States Department of Housing and Urban Development (USDHUD), 2018. QuickFacts Colleton County, South Carolina; Aiken County, South Carolina; Calhoun County, South Carolina; Hampton County, South Carolina; Bamberg County, South Carolina. https://www.census.gov/quickfacts/fact/table/colletoncountysouth carolina, aikencountysouthcarolina,calhouncountysouthcarolina,hamptoncount ysouthcarolina,bambergcountysouthcarolina/PST045218.

Wilber, M., Chinn, S., Beasley, J., Boughton, R., Brook, R., Ditchkoff, S., Fischer, J., Hartley, S., Holmstrom, L., Kilgo, J., Lewis, J., Miller, R., Snow, N., VerCauteren, K., Wisely, S., Webb, C., Pepin, K., 2020. Predicting functional responses in agroecosystems from animal movement data to improve management of invasive pests. Ecol. Appl. 30, 1.

Wilcox, J.T., van Vuren, D.H., 2009. Wild pigs as predators in oak woodlands of California. J. Mammol. 90 (1), 114-118.

Wirthner, S., Frey, B., Busse, M.D., Schütz, M., Risch, A.C., 2011. Effects of wild boar (Sus scrofa L.) rooting on the bacterial community structure in mixed-hardwood forest soils in Switzerland. Eur. J. Soil Biol. 47 (5), 296-302.

Wyckoff, A.C., Henke, S.E., Campbell, T.A., Hewitt, D.G., VerCauteren, K.C., 2012. Movement and habitat use of feral swine near domestic swine facilities. Wildl. Soc. Bull. 36 (1), 130-138. 